\title{
The time to lead
}

\section{ACRL seeks nominees for section offices}

tanding for ACRL section of ce is an optant issues affecting academic and research librarians in the 21st century, gain leadership experience, and build ties with colleagues. It is also an opportunity to be of service to your ACRL section community, ensuring that it continues to nurture the development of new members and forge deeper connections to the profession.

\section{ACRL section officers}

Candidates for vice-chair/chair elect, secretary, and members-at-large of ACRL sections are selected by the Nominating Committee of each section. If you would like to nominate someone or be nominated yourself, contact the chair of the appropriate section Nominating Committee prior to the ALA Annual Conference in Anaheim. Terms of of ce will begin on July 1, 2009.

\section{9 section nominating committee chairs}

African American Studies Librarians: Carmelita Pickett, Emory University, cnpicke@emory.edu

Anthropology and Sociology: JoAnn Jacoby, University of Illinois at Urbana-Champaign, jacoby@uiuc.edu

Arts: N/A. Contact: Lucie Stylianopoulos, University of Virginia, lucie@virginia. edu

Asian, African, and Middle Eastern: N/A. Contact: Ravindra N. Sharma, Monmouth University, rsharma@monmouth. edu
College Libraries: Gillian S. Gremmels, Davidson College, jigremmels@davidson. edu

Community College and Junior College Libraries: N/A. Contact: Lora Mirza, Georgia Perimeter College, mmirza@gpc.edu

Distance Learning: N/A. Contact: Patrick Mahoney, Mitre Corporation, scimitar12@yahoo. com

Education and Behavioral Sciences: Mary Jane Brustman, University at Albany, brustman@uamail.albany.edu

Instruction: Lisa Hinchliffe, University of Illinois at Urbana-Champaign, ljanicke@uiuc. edu

Law and Political Science: N/A. Contact: Ann Marshall, University of Rochester, amarshall@library.rochester.edu

Literatures in English: Kristine J. Anderson, Purdue University, kja@purdue.edu

Rare Books and Manuscripts: Edwin C. Schroeder, Yale University, edwin. schroeder@yale.edu

Science and Technology: Catherine B. Soehner, University of Michigan, csoehner@umich.edu

Slavic and East European: N/A. Contact: Teresa Tickle Miller, Michigan State University, ticklet@msu.edu

University Libraries: Cheryl Middleton, Oregon State University, Cheryl. Middleton@oregonstate.edu

Western European Studies: Katalin Radics, University of California-Los Angeles, kradics@library.ucla.edu

Women's Studies: Pamela Mann, University of Texas-Austin, pamela.mann@mail. utexas.edu $\boldsymbol{n}$ 